\section{Commentary: Aortic valve repair in children: Art or science?}

\author{
Bahaaldin Alsoufi, MD
}

A quote attributed to German philosopher Friedrich Schlegel states: "Every art should become science and every science should become art" This statement is likely true for all reconstructive cardiac surgeries, most definitely valve repairs. During the past 3 decades, pioneering surgeons have explored methods to repair cardiac valves using various techniques. Improved understanding of valve morphology, mechanism of function, and pathophysiology resulted in refinements in these techniques, with subsequent superior repair outcomes and durability. Initially, successful repair was accomplished essentially by master surgeons who developed these procedures and accumulated large experience. Increasing implementation and reproducibility of these procedures was only possible after introduction of science to the art of repair, and standardization of valve assessment and reconstruction techniques. In adult cardiac surgery, widespread embrace of valve repair was initially for the mitral valve, with the aortic valve lagging behind until the recent 2 decades.

The aortic valve and root work as a single functional unit, with valve competency depending on fine interface between the various elements of this unit, including aortic cusps, annulus, sinuses, and sinotubular junction. ${ }^{1}$ Better understanding of the complex function of this unit and pathophysiology of various disease processes contributed to improved repair strategies. The current principles to achieve durable aortic valve repair rely on normalization of cusp geometry and creation of adequate cusp tissue and coaptation area, in addition to annular reduction and stabilization. ${ }^{1}$ In adult aortic valve repair, it is agreed that cusp effective height (ie,

\footnotetext{
From the Department of Cardiovascular and Thoracic Surgery, University of Louisville School of Medicine and Norton Children's Hospital, Louisville, Ky.

Disclosures: The author reported no conflicts of interest.

The Journal policy requires editors and reviewers to disclose conflicts of interest and to decline handling or reviewing manuscripts for which they may have a conflict of interest. The editors and reviewers of this article have no conflicts of interest.

Received for publication June 5, 2021; revisions received June 5, 2021; accepted for publication June 18, 2021; available ahead of print June 24, 2021.

Address for reprints: Bahaaldin Alsoufi, MD, Department of Cardiovascular and Thoracic Surgery, University of Louisville School of Medicine, Norton Children's Hospital, 201 Abraham Flexner Way, Suite 1200, Louisville, KY 40202 (E-mail: balsoufi@hotmail.com).

JTCVS Techniques 2021;8:138-9

2666-2507

Copyright (c) 2021 The Author(s). Published by Elsevier Inc. on behalf of The American Association for Thoracic Surgery. This is an open access article under the CC BY-NC-ND license (http://creativecommons.org/licenses/by-nc-nd/4.0/).

https://doi.org/10.1016/j.xjtc.2021.06.027
}

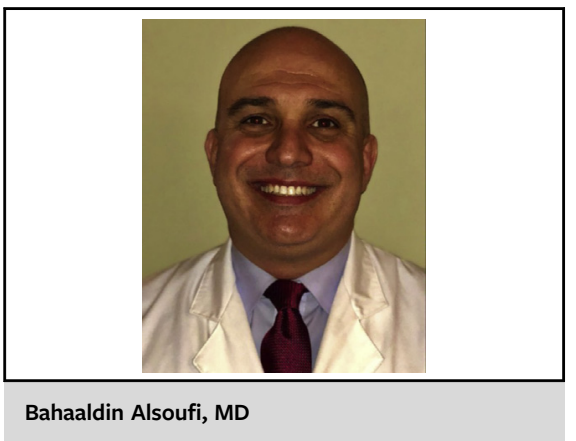

CENTRAL MESSAGE

Adding science to the art of valve repair improves results and enhances reproducibility. This task is more challenging in children due to factors such as diverse valve pathologies and patient growth.

distance between central free margin and annular plane) of 9 to $10 \mathrm{~mm}$ and adequate amount of cusp tissue, with the geometric height (ie, distance from the nadir of the cusp to the central free margin) serving as a surrogate parameter, are both important markers for repair success and durability. $^{2}$ Calipers were designed to allow intraoperative measurement of these heights and aid with the repair, and a number of studies validated the role of these measurements in predicting repair success. ${ }^{3}$

Bouhout and colleagues ${ }^{4}$ from Montreal aimed to create a nomogram to calculate the normal aortic valve cusps effective height according to body surface area in pediatric patients. For that purpose, the authors reviewed echocardiograms $(n=714)$ of children from their institution. They measured the effective and geometric heights and created a table that lists the mean measurements of these 2 heights based on incremental body surface area. For example, effective and geometric heights for a small infant with body surface area of $0.2 \mathrm{~m}^{2}$ are $4 \pm 1 \mathrm{~mm}$ and $8 \pm 1 \mathrm{~mm}$, whereas they are $9 \pm 1 \mathrm{~mm}$ and $19 \pm 1 \mathrm{~mm}$ for an adult-size child with body surface area of 1.8. The authors believe that knowing these measurements gives surgeons some guidance and helps achieve successful aortic valve repair. ${ }^{4}$

In general, valve repair in children is more challenging than in adults, especially when repair is performed at very young age. Many factors contribute to these challenges. There are technical issues related to small size and difficult exposure. Additionally, structural valve anomalies 
are more common in children than in adults and the diverse congenital anomalies make standardization of repair less likely attainable. Most importantly, durability of valve repair depends on many factors that are usually inherent to valve pathology and surgical repair strategy (eg, degeneration of patch material). In children, a very important additional factor that affects repair durability is the patient's growth, especially when repair is performed in small children. The nomogram proposed by the group from Montreal is a good effort to add some science to the art of aortic valve repair in children. Its applicability remains to be demonstrated. The incidence of unicuspid and bicuspid aortic valve is higher in children and this nomogram covers tricuspid aortic valves only. Moreover, the correlation between effective and geometric heights and repair durability, while established in adults, is not yet validated in children. There are no small-sized calipers that could aid with intraoperative measurements, and achieving the desired height (whether with cusp reconfiguration, addition of patch material, or cusp excision and replacement) might work during the early period but would not be adequate over the growth period. The concept of cusp oversizing to increase geometric height and allow some redundancy to account for child's growth is restricted to a certain degree in small children due to the risk of development of complications such as increased valve gradient and coronary obstruction. Most importantly, the lack of ideal patch material with retraction, calcification, or fibrosis continue to be important limiting factors.

Adding science to the art of valve repair with better understanding of ideal anatomy and how the aortic valve functions allows for standardization of valve assessment and repair techniques, and results in superior and reproducible results. Several inherent issues in children make this goal less realistic and this fact continues to affect repair outcomes and replicability. Therefore, valve repair remains an acquired artistic skill for surgery in all age groups, more so in children.

\section{References}

1. Ram D, Bouhout I, Karliova I, Schneider U, El-Hamamsy I, Schäfers HJ. Concepts of bicuspid aortic valve repair: a review. Ann Thorac Surg. 2020;109 999-1006.

2. Bierbach BO, Aicher D, Issa OA, Bomberg H, Gräber S, Glombitza P, et al. Aortic root and cusp configuration determine aortic valve function. Eur J Cardiothorac Surg. 2010;38:400-6.

3. Schäfers HJ, Bierbach B, Aicher D. A new approach to the assessment of aortic cusp geometry. J Thorac Cardiovasc Surg. 2006;132:436-8.

4. Bouhout I, Chauvette V, Rong W, Raboisson M-J, El-Hamamsy I, Poirier N. The normal aortic valve leaflets effective height in pediatric patients: a guide to aortic valve repair. J Thorac Cardiovasc Surg Tech. 2021;8:135-7. 